\title{
Postural Control in Man: The Phylogenetic Perspective
}

\author{
Albert Gramsbergen \\ University of Groningen, Medical Physiology, 9713 AV Groningen, the Netherlands
}

\begin{abstract}
Erect posture in man is a recent affordance from an evolutionary perspective. About eight million years ago, the stock from which modern humans derived split off from the ape family, and from around sixty-thousand years ago, modern man developed. Upright gait and manipulations while standing pose intricate cybernetic problems for postural control. The trunk, having an older evolutionary history than the extremities, is innervated by medially descending motor systems and extremity muscles by the more recent, laterally descending systems. Movements obviously require concerted actions from both systems. Research in rats has demonstrated the interdependencies between postural control and the development of fluent walking. Only 15 days after birth, adult-like fluent locomotion emerges and is critically dependent upon postural development. Vesttibular deprivation induces a retardation in postural development and, consequently, a retarded development of adult-like locomotion. The cerebellum obviously has an important role in mutual adjustments in postural control and extremity movements, or, in coupling the phylogenetic older and newer structures. In the human, the cerebellum develops partly after birth and therefore is vulnerable to adverse perinatal influences. Such vulnerability seems to
\end{abstract}

Reprint requests to: Albert Gramsbergen, University of Groningen, Medical Physiology, 9713 AV Groningen, The Netherlands; e-mail: a.a.gramsbergen@med.rug.nl

O 2005 Freund \& Pettman, U.K. justify focusing our scientific research efforts onto the development of this structure.

\section{INTRODUCTION}

"Posture" might be defined as the position of the body in relation to the gravitational vector and of the body-segments in relation to each other, both in static and in dynamical conditions (e.g., Gramsbergen, 1998). Deficient postural control in human infants is considered an important factor in several developmental disorders concerning motor control (Aicardi \& Bax 1992), and for that reason, this aspect has been in the center of interests of rehabilitation therapists, pediatric neurologists and neurobiologists, for example. When considering postural control from a neurophysiological point of view, it is important to realize that this control as such is an abstraction from motor control. Indeed, abnormalities in motor patterns might be traced back to abnormalities in controlling the trunk or to abnormalities in maintaining equilibrium. Therefore, assessing the reactions to perturbations or analyzing such motor patterns as reaching in babies or rearing in rats can help to investigate this specific aspect of motor control. Yet, movements and postural control in normally functioning individuals are fully integrated and distinguishing one or the other aspect in an ongoing movement basically is impossible. On the other hand, it should be realized that the trunk and neck, instrumental in keeping the body erect or straight, and the extremities involved in locomotor and manipulative movements have different phylogenetic histories. The trunk has a history stretching 
over billions of years, whereas the extremities are from a more recent past, and the fine and delicate neural control of finger move-ments emerged only a few million years ago. Interestingly, these differential ancestries are reflected in important differences in those sub-systems of the central nervous system that govern the trunk and extremity muscles, respectively. A similar example is the visual system in man, in which the fovea, projecting via the geniculate nucleus to the visual cortex, is fully integrated with the subcortical retino-tectal system active in directing gaze (Deacon, 1992). The latter system (involving peripheral retinal fields, tecto-spinal, and tectobulbar projections) developed early in evo-lution, whereas acuity and color vision (depending upon tightly packed cones in the fovea and on cortical circuitry) has developed only recently. These examples illustrate that phylogenetically older systems can persist alongside newer systems, both being fully integrated into one functioning system. Yet, differences between older and newer elements can remain apparent, generally by their circuitries and localization, often by their develop-mental pathways and sometimes by differential vulnerabilities to trauma. This is the background for considering in this essay some evolutionary aspects of postural control and movements.

\section{EVOLUTION OF TRUNK AND EXTREMITIES}

Evolution is based upon the selection of those variations in the genome that provide groups of individuals with increased adaptational possibilities (Gould, 2000). Evolution principally is an autonomous process, new behaviors became possible and new structures spontaneously emerged during evolution rather than being caused by it (Dover, 2000). The possibilities to make use of alternative and richer food supplies, particularly in circumstances of diminishing resources, have given certain varieties decisive advantages over others who could not, and the need for food in particular has been considered a powerful selective agent throughout evolution. The evolution from ancient forms of animal life clearly illustrates this point. The earliest animals reside in the water, remaining on one place, and wait for food to come to them. Sea anemones with a nervous system consisting of a diffuse network of neural cells are examples of such 'primitive' creatures. Sea anemones do move by changes of posture, they even present moods by postural changes (Reisinger, 1926) and survive by digesting the food passing by. More advanced are fishes, belonging to an early order of vertebrates. Fishes are able to move towards their food sources. Swimming in fish is effected by undulating movements of the trunk, mostly in a side-to-side fashion. Their side-fins are not true extremities but rather serve to stabilize the body during swimming.

Amphibiae, more advanced vertebrates, are furnished with extremities that enable them to move effectively on firm ground from one pond to the next, allowing them to find fresh water or richer food sources. Amphibiae developed lungs, which obviously are an essential requirement to remain in terrestrial conditions for extended periods. The extremities, particularly the muscles counteracting gravity, serve to keep the belly free from the ground (Romer, 1969), but progression in amphibiae, as in fish, is mainly effected by undulatory movements of the trunk.

In reptiles, the extremities are more powerful and in some varieties provide animals with a fair degree of agility (obviously, snakes are in this respect an exception among reptiles). Interestingly, the thecodonts (to a certain degree resembling crocodiles) living around 240 million years ago in the triassic period, tended towards bipedal locomotion (Chatterjee, 1982). Other species of the thecodontiae obviously were able to fly. Some varieties lived in trees, others must have climbed trees and glided back to the ground, and still other 
forms actively flew. Obviously, these thecodonts were transitional forms between reptiles and birds.

At a later stage in evolution, mammals diverted from the reptiles, giving birth to lifestock. Their strong and long extremities allow quadrupedal mammals to move swiftly and efficiently. Cats, dogs, horses, for example, are able to walk slowly but also to trot or gallop and jump, all depending on subtle adjustments in interand intra-limb coordination (Grillner, 1981). The extremity movements in mammals have taken the primacy in propulsion, whereas the control of the trunk subserves keeping the trunk and the head stabilized in space. Hominids are specifically distinguished from monkeys and apes by their bipedal gait. The body is lightly built; the legs are long and strong, the arms being relatively short. Whether the need for food or a change in the diet has been the selective agent in the evolution from quadrupedal to bipedal gait and other developments is not clear. Their evolution is indicated by an increase in brain size, by the ability to communicate effectively, by increasingly efficient ways to walk swiftly over long distances, and by their manual skills, enabling them to build and use fine tools, to mention only a few aspects. These affordances have tremendously increased the possibility to exploit resources efficiently, to integrate into social communities, to share new knowledge and by that, to solve common problems. These aspects decisively have given them advantages over their more primitive predecessors.

Based on biochemical extrapolations, it is estimated that only between eight and five million years ago, the first hominids, the australopithecines, split off from the ape family (White et al., 1994; Leakey et al., 1995; Ward et al., 2001). D.C. Johanson in Mary Leaky's team in 1978 in Tanzania discovered the footprints of three australopithecus individuals in volcanic ash, which solidified after they had crossed it. Estimates based on skeletal remains of these homo australopithecus afarensis indicated that they were
1 to 1.5 meters tall, weighed about 50 kilograms, with a brain size of 400 to $500 \mathrm{~mL}$, which is about one third of that in modern humans. Footprints, as well as the shape of the hips, knees, and femur, indicate that such individuals walked bipedally (Martin, 2002). The toes being closely together and the big toes not being opposed to the other toes resemble the foot and the position of the toes in modern man. Based on artifacts that were found in the area, such individuals apparently were able to produce tools.

About 2.4 million years ago, new types of hominids appeared in eastern and southern Africa, with a more advanced and distinctly 'human' build, the homo habilis, the handy men, 1 to 1.5 meters tall and with a brain size of between 500 and $800 \mathrm{~mL}$. From 1.8 million years ago, a new variety developed in Africa, the homo erectus, being 1.3 to 1.5 meters tall and distinguished from the earlier homo habilis by an increased brain size of 800 to $1200 \mathrm{~mL}$. Hominids with these characteristics obviously migrated from one million years ago to Asia, the Indonesion isles, and possibly to Europe as well (Stringer, 2002). Based on artifacts that were found in Georgia, it appeared that they used tools made of wood, which must have required rather sophisticated fabrication techniques or, advanced manipulative skills. Homo sapiens, the variety to which modern humans belong, emerged about four hundred thousand years ago. These hominids had a larger brain and a skull that approached the modern form. A wellknown specimen is the homo neanderthalensis, and similar skeletons have been found elsewhere in Germany, in Wales, in England, and in France. They lived until 30,000 years ago, had brain sizes ranging between 1200 and $1750 \mathrm{~mL}$, weighed 65 kilograms, and were up to 1.7 meters tall. The earliest modern men were taller (between 1.6 and 1.85 meters), but with a brain size approximating that of the neanderthaler man (Stringer, 1992). They had less prominent bow ridges and a less robust skeleton, longer legs, and the shape of their 
hip joints and pubic bone suggest that they moved their legs in a modern fashion (Martin, 2002). The older fossils of these modern men date back to one hundred thousand years ago, and this indicates that the homo neanderthalensis and the modern man have coexisted for a considerable period. The spread of these modern humans over Africa, Asia, and Europe seems to have occurred from around forty thousand years ago (Stringer, 1992), leaving products of their manual skills and artistic talents at several places, among those in the Cro Magnon caves in the Périgord in France.

The question on the relation between the emergence of the bipedal gait and the increase in brain size has repeatedly been raised in the past. The issue at stake is whether it was the larger brain with greater motor capacities that has enabled the hominids to keep balance and to move the legs in a sophisticated fashion, the alternative being that the increase in brain size followed the development of bipedal gait. Studying the trends in the body weight-brain weight ratios in earlier and more recent hominids solves this question. The different varieties of australopithecines walking bipedally, lived from about four until one million years ago, with brain sizes ranging from 400 to $500 \mathrm{~mL}$ (Wood 2002). Only since the emergence of the homo habilis (about 2 million years ago), along with the homo erectus ( 1.8 million years ago), and the homo sapiens (from around 100,000 years ago), has the brain-to-body weight ratio deflected more steeply from that in the australopithecines and in phylogenetically older apes. The 2.5- to 3fold increase in brain size, from around 500 grams until around 1400 to 1500 grams, was paralleled by a moderate increase in body weight from an average value of between 40 and 50 kilograms for australopithecines to 60 and 70 kilograms in modern man (Deacon, 2002, Stringer, 2002). This observation implies that the increase in brain size, also coined cephalization, started about two million years after hominids started walking bipedally. Obviously, this trend in brain size is based upon global approximations, and indications for regional deviations from these trends could not be considered.

The increases in the dimensions of the skull (because of the larger brain) in conjunction with decreases in the size of the inner pelvis in more recent hominids because of the erect gait and changes in leg movements (see, above) were among the factors that induced that term age in human babies is at an early stage of brain development and that a relatively large part of brain development occurs in babies after they are born (Deacon, 2002). An additional factor for birth at an early stage is that the metabolic demands of the brain mass at later stages of intra-uterine development cannot be met by the capacity of the maternal placenta. The consequences of a "premature, but physiological" birth at term age, (the term physiologische Frühgeburt is from Portmann) for behavioral and neurological development were discussed extensively by Prechtl (1984).

\section{INNERVATION OF TRUNK AND EXTREMITY MUSCLES}

The emergence of extremities, the erect gait, and the possibility to use the hands and fingers for manipulating objects have been paralleled by morphological changes in muscles, as well as by changes in fiber type distributions and changes in the morphology of the skeleton, as well as by important changes in the central nervous system. Skeletal fragments and fossils do allow the reconstruction of evolutionary pathways, remains of tools and artistic expressions suggest a certain stage of manipulative skills, but no traces of brain tissue are left. However, comparison of neuroanatomical details in still existing members of evolutionary ancient orders, such as fish, amphibians, and reptiles with mammals and trends in these changes enable to reconstruct globally the evolution that has taken place in brain systems and 
circuitries. Within the scope of this essay, a few relevant phylogenetic aspects of motor systems will be discussed.

In fish, propulsion is effected by rhythmic and undulating trunk movements. The vast and detailed investigations in the Lamprey by Sten Grillner and his group (1991) have given insight into the details of the neural circuits involved, and similar neural mechanisms are probably effective in other limbless vertebrates. These circuits consist of interacting groups of excitatory and inhibitory neurones communicating with a variety of neurotransmitters and neuromodulators, producing an alternating activation and relaxation of the muscles at the right and left side of the trunk. These circuits, or oscillators, in each of the trunk segments have been coined Central Pattern Generators (CPGs), and a time-delay in their activation leads to a wave-like, rostro-caudal progression of muscle contractions, an undulating movement and by that, to propulsion of the body. Medially descending projections from the brain, analogous to the reticulospinal tract (RetST) in mammals induce the start and halt of these movements, and these also can increase and decrease swimming speed by changing the delay-times between the activation of the respective CPGs (Ten Donkelaar, 1982, Grillner et al., 1991).

Amphibians and reptiles live on firm ground, and their four extremities keep the body off the ground. In these orders, laterally descending fiber projections have evolved in the spinal cord, in addition to the phylogenetically older and medially descending projections. The laterally descending fiber projections activate the motoneurones of the extremity muscles. The projections emerge from brain stem nuclei at the contralateral side and most important among these are the red nuclei in the brain stem (giving rise to the rubro-spinal tract, RubST). Its activity in the amphibiae and the reptiliae is superimposed upon the activity in the medially descending systems (Kuypers, 1982), implying that progression in these animals, is effected by the pattern of trunk movements. An activation of the antigravity muscles in the extremities lifts the body and increases the effectivity of locomotion. Still, some animals are able to make fairly sophisticated leg movements, such as the frog, which, as Ebbeson (1976) has noted is able with its hindlegs to remove a grain of sand from the eye. The medially descending fibers stemming from reticular, vestibular, and tectal nuclei mainly project to the motoneurones of trunk muscles and the activity in these projections is functionally related both to progression and postural activities (Peterson et al., 1979; Vinay et al., 1998; Vinay et al., 2000).

Quadrupedal mammals have both laterally and medially descending motor projections in the spinal cord, but the functional importance of the laterally descending systems (the RubST and also the more recent corticospinal tract, the CST) and the central motor areas involved in steering extremity movements have drastically increased (Ten Donkelaar, 1982). Indeed, in quadrupeds propulsion is primarily effected by extremity movements rather than by trunk movements.

In quadrupeds, the RubST plays an important role in activating the extremity muscles involved in locomotion. The RubST particularly governs the activation of the proximal extremity muscles as indicated by the localization of the terminal fields of the projecting fibers (see Kuypers, 1982 for details and references). The red nucleus receives much of its input from the deep cerebellar nuclei. Electrical recordings from these nuclei and from the red nucleus in cats have shown electrical activity in phase with walking movements (Orlovsky, 1972). Data from monkeys and the results from a series of elegant experiments in rats (Whishaw et al., 1986) suggest that the RubST is also involved in skillful extremity movements. The crossed portion of the CST in quadrupedal animals, other than in man, probably plays a main role in modulating the afferent information as most fibers terminate in the dorsal horn (Porter \& Lemon, 1993). 
In apes and even more so in man, the CST emerging from several cortical fields has become the most important descending motor tract. The CST (and particularly the fibers from the primary motor cortex) allows for the-as Kuypers called them-fractionated finger and toe movements by virtue of monosynaptic connections between cortical neurones and motoneurones in the spinal cord (Lawrence \& Kuypers, 1968; Kuypers, 1982). These findings have been corroborated by stimulation experiments, by electrical recordings during hand movements, and by imaging techniques. The RubST in man might still be involved in the activation of proximal extremity muscles (Kuypers, 1982). However, as the magnocellular part of the red nucleus in man is only small (this specific part is the source of the RubST in lower vertebrates), others doubt whether this projection in man persists into adulthood, and if so, whether it plays an important role (Holstege, 1991).

Rhythmic leg movements, such as those during walking in quadrupeds and in man, probably are produced by specialized neural circuits in the brain stem and spinal cord, and these circuits (similar to those circuits in fish that produce the axial swimming movements) are known as CPGs (Grillner, 1981, Cazalets et al., 1995, Kjaerulff \& Kiehn 1996, Cazalets, 2001). The CPGs for the hindleg movements alternatingly activate leg flexors and leg extensors; CPGs have been identified at upper lumbar levels in rats and also in cats, but slightly more caudally. CPGs most probably exist in man as well (Forssberg, 1985, Forssberg \& Dietz 1997). Control of an upright and straight posture during standing or bipedal locomotion, and simultaneously the performance of arm and hand movements, poses intricate cybernetic problems in man. To this, CPGs in close cooperation with several areas in the cerebral cortex, the cerebellum, the basal ganglia, as well as a strong myelinated corticospinal tract and a multitude of ascending tracts to thalamus and cerebellum are acting together with brain stem areas involved in the control of posture and the maintenance of equilibrium during walking.

\section{POSTURAL CONTROL AND THE DEVELOPMENT OF WALKING}

The different phylogenetic ancestries of the trunk and extremities are reflected in the different timescales of the development of the neural systems underlying trunk and limb movements, respectively. Studies into the neuro-ontogeny of postural control and the control of movements like walking and reaching indeed have demonstrated that both aspects follow separate (although inter-dependent) trajectories. Investigations into reaching by human babies in the first years of life, performed by Hadders-Algra and her group, have shown that the efficiency and the fluency in the movement trajectories of the arms are related to the timing and the extent of adjustments in trunk muscles (Hadders-Algra et al., 1996, Van der Fits et al., 1999). Postural control changes from a feed-back type of control with reactions to self-generated movements of the reaching arm (or reactions to perturbations) to a feed-forward type of control, in which postural adjustments before and during the reaching movement are elements of one integrated movement program (for details on this development as well as on stages therein, see Hadders-Algra, this issue). Similarly, in the development of free walking during the first years of life it appears that the control of posture, as indicated by the ability to stand and to maintain equilibrium during walking is the limiting factor for an effective and fluent performance of such tasks.

Also in rats, the development of postural control and the control of extremity movements follow different time scales. Altman and his group (Altman \& Bayer, 1984) studied the development of the spinal cord in rats and demonstrated that the motoneurons for the extremity muscles develop about one day ahead of those for the trunk 
muscles. The motoneurones in the cervico-thoracic and lumbo-sacral intumescences innervating the rostral and caudal extremities develop on embryonic day (E)12 and E13, whereas those for the innervation of the trunk muscles are born only at E14 or later (rats are born after a gestational period of 21 to 22 days). On the other hand, the medially descending fiber tracts in rats innervating the motoneurones of the trunk muscles have reached caudal levels already around E14 (Lakke, 1997), whereas the laterally descending systems develop only between 1 week thereafter (the RubST; Lakke, 1997) or still later (the CST; Jones et al., 1982, Joosten et al., 1989, Lakke, 1997). As to the development of the central structures involved, most information is known on the development of the cerebellum. The cerebellum is involved in adjusting postural control to ongoing movements (Grillner, 1981, Gramsbergen, 1998, see also Swinny, this issue) and in the fine-tuning of the activity of spinal motoneurones. The Purkinje cells, the deep cerebellar nuclei (the output nuclei) and the so-called precerebellar nuclei (feeding their input to the cerebellum) all develop very early in ontogeny. However, granular cells (the most numerous cell type in the brain) with their parallel fibers impinging upon the Purkinje cells develop markedly late. In the human, the cerebellar growth spurt occurs from shortly before birth well into the first year after birth (Dobbingm, 1981), but in the rat, this development takes place completely after birth (Altman \& Bayer, 1996). Cortical circuitry in the cerebellum therefore is established only at a relatively late stage in the development of motor control.

These few examples illustrate the complicated timescales in the development of the neural systems involved in extremity movements (the 'lateral system'), in trunk movements (the 'medial system'), and in the cerebellum, which is involved in the integration of these both aspects (see, below).

Our own research into the ontogenesis of locomotion in rats sheds further light onto the functional aspects of movement control. A few considerations point to the rat as the experimental animal of choice for neuro-ontogenetic research. Rats are born at an early stage of brain maturation, which allows investigation of the early stages of development in their postnatal period. Rats of around 13 days after birth might be compared, as the stage of brain development is concerned with humans around term age (Romijn et al., 1991, see also Clancy et al., 2001). In addition, rodents in an evolutionary sense are relatively modern animals. Taking the CST, the most modern descending fiber system as an indicator, in rats this tract descends as far as lumbar levels and at cervical levels invades the ventral horn (Jones et al., 1982). It has been suggested that the CST is involved in skilled forepaw movements (Whishaw \& Metz 2002. In these respects, rats are more advanced than e.g., cats or dogs.

Shortly after birth, when rats move from their position, movement is effected by undulating movements of the trunk. Two or three days later, the rostral extremities assist in lifting the body from the floor (Gramsbergen, 1998) and another two or three days later, the hindlegs also participate in crawling. The rat then still moves by undulating trunk movements during locomotion very much like those in adult amphibians (and also resembling those in human babies). At the age of about 1 week, rats can stand on their fours and make a few staggering steps. The bouts of such walking movements increase, but the rats keep moving slowly, often with a tremor in the trunk (Altman \& Sudarshan, 1975, Westerga \& Gramsbergen, 1990, Geisler, 1993). At P15, in the course of 1 day, this immature pattern is replaced by a smooth and adult-like walking pattern (Westerga \& Gramsbergen, 1990).

From then onward, the feet and limbs remain adducted, the fluency and the speed of walking increase remarkably, and equally striking are the sudden variations in walking speed that can occur. This transition is accompanied by changes in EMG patterns of the major hindlimb muscles. Until the 
$15^{\text {th }}$ day, EMG recordings of the gastrocnemius muscles, the soleus, and the tibialis muscles show irregular activity. The gastrocnemius muscle (the limb extensor) and its antagonist, the tibialis anterior muscle (the flexor), often show simultaneous activity (Westerga \& Gramsbergen, 1993, 1994), much like the cocontractions that have been described by Forssberg (1985) in the legs of human babies during "infantile stepping". After the transition into the adult-like walking pattern, clearly delineated EMG bursts occur. A long 'tonic' burst in the gastrocnemius muscle accompanies the stance phase, and a brisk burst in the tibialis anterior muscle precedes the onset of the swing phase; the co-contractions in the antagonistic muscles have disappeared after this shift (Westerga \& Gramsbergen, 1993).

At earlier ages, the lateral and medial longissimus muscles in the back are irregularly activated during locomotion. From P16, the medial back muscles are continuously active during walking and standing and the laterally located back muscles are activated in phase with the stepcycle of the hindlegs (Geisler et al., 1997). Then, the muscle is active during the contraction of the contralateral gastrocnemius muscles (i.e. during the stance phase at that side). During later development, a further rearrangement in the activity of the back muscle activity occurs. From P21, the lateral back muscle is activated during the contraction of the gastrocnemius muscle at the ipsilateral side, and this shift possibly relates to an increased efficiency of such coupling (Gramsbergen et al., 1999).

Based on these results, we concluded that postural control is the decisive factor in the development of the adult-like walking pattern. Strong additional evidence has been obtained in experiments in rats subjected to deprivation of part of the vestibular information, by plugging both horizontal semi-circular canals at P5. Behavioral observations in these animals indicated that such interference with vestibular input leads to a marked retardation in those patterns requiring a high degree of postural control, such as grooming (retarded by 1 or 2 days) and rearing (standing on the hindlegs without support) by 4 to 5 days (Geisler et al., 1996). This delay leads to a retardation in the development of fluent walking by 3 to 4 days (Geisler et al., 1996; Geisler \& Gramsbergen, 1998). The activation of the long back muscles in phase with the hindleg movements, which in normal rats occurs around P16), is also delayed by at least 2 days. Moreover, this coupling remains highly variable throughout the observation period of 45 days.

In summary, our results in rats indicate that the neural development of postural control (involving an intricate feed-forward programming of adjustments in 'postural muscles') is the limiting factor for the development of fluent type of walking. Similarly, in human babies and in children, feedforward control of posture, as indicated by specific patterns of activation of muscles involved in postural control, is the prerequisite for efficient reaching movements (Hadders-Algra et al., 1996, Van der Fits et al., 1999) and for walking as well (Forssberg \& Dietz, 1997).

Many brain structures are involved in programming mutual adjustments in the trunk and limbs during such complex movements. From brain pathology in the elderly, it is well known that anomalies in the basal ganglia seriously interfere with such movements (Visser \& Bloem, this issue), but, unfortunately not much is known about the development of the basal ganglia in man, nor in e.g. rats. Similarly, the sensorimotor cortices must play a key role in such adjustments as indicated by the serious motor impairments occurring after internal capsule lesions at the neonatal age. Such impairments in the human particularly become apparent from the age at which functional connections between CST and spinal motoneurons and interneurons are established.

Cerebellar processing plays an important role as well in programming the adjustments in trunk and extremity movements during complex motor programs, or, in coupling postural control to limb 
movements (Grillner, 1981, Gramsbergen, 1998). A few arguments for a key role of the cerebellum in these adjustments are the following. Firstly, anatomic data indicate that the cerebellum, more than any other neural system, is minutely informed on the orientation of the body in space, on the positions of the body segments in relation to each other by proprioceptive and vestibular input, and also indirectly by visual and auditory input (Grillner, 1981, Brodal, 1992). The cerebral motor cortex informs the cerebellum on intended movements by massive projections via the pontine nuclei. The effects of motor commands are monitored by the cerebellum by afferent input from the ventral spinocerebellar tract (conveying information on the activational state of the motoneurones or the status of the motor command) and via the dorsal spinocerebellar tract (conveying information on proprioceptive feedback or, the effect of the motor command). Based on this knowledge, it seems highly plausible that the cerebellum plays a key role in adjusting the recruitment of motoneuronal activities.

Secondly, cerebellar anomalies are related to a loss of fluency in movements and to a retarded development of complex motor patterns like walking. In Down's syndrome, in which cerebellar development is both decreased and retarded, the development of postural control and motor performance is delayed and often remains suboptimal to a larger or lesser degree (Henderson et al., 1981, Shumway-Cook \& Woollacott, 1985). In our own experiments in rats, we ablated a cerebellar hemisphere at the $2^{\text {nd }}, 5^{\text {th }}$, and $10^{\text {th }}$ days, and at later ages as well. In animals lesioned until the $10^{\text {th }}$ day, we demonstrated that motor development until the $15^{\text {th }}$ day (the age at which the transition into the fluent walking pattern normally merges) is normal, but that this shift did not occur in rats subjected to a cerebellar hemispherectomy (for details and references, see Gramsbergen, 1998).

Based on these considerations, we suggested that, the cerebellum plays a key role in the feed- forward programming of postural adjustments along with complex movement programs.

\section{EPILOGUE}

Postural control in humans is dependent, to a large extent, upon trunk and neck muscles, as well as on antigravity muscles in the legs. The discussion above $h$ as indicated that in vertebrates, the axial muscles (from fish onward) and their neural control have a phylogenetically older history than the flexor and extensor muscles involved in walking and the distal extremity muscles in manipulating. Data on the ontogeny of motor control indicate that the skeleto-muscular structures and neural systems involved in postural control develop partly ahead and partly later than the structures and systems involved in steering extremity movements.

The cerebellum obviously has a pivotal role in mutual adjustments in the functioning of the phylogenetically older and newer structures. From a phylogenetic perspective, it is interesting to note that the cerebellum increased its relative size from reptiles onward, particularly in birds and mammals (Crosby, 1969). In higher vertebrates, the cerebellum plays a prominent role in the control of movement and in the acquisition of motor skills. The cerebellum develops partly after birth in the human and therefore is vulnerable to adverse perinatal influences (such as deficient food supply, prolonged treatment with corticosteroids etc; Gramsbergen, 1998). Both factors seem to justify focusing our scientific research efforts on the development of this structure.

\section{REFERENCES}

Aicardi J, Bax M. 1992. Cerebral palsy. In: Aicardi J, ed, Diseases of the Nervous System in Childhood. (Clinics in Developmental Medicine, Nos. 115118). London, UK: MacKeith Press, Oxford Blackwell Scientific Publications; 330-374 
Altman J, Bayer SA. 1984. The development of the rat spinal cord. Adv Anat Embryol Cell Biol 85: 1-164.

Altman J, Bayer SA. 1996. Development of the Cerebellar System. Boca Raton-New York-LondonTokyo: CRC Press; 1-783.

Altman J, Sudarshan K. 1975. Postnatal development of locomotion in the laboratory rat. Anim Behav 23: 896-920.

Brodal P. 1992. The cerebellum. In: Brodal P, ed, The Central Nervous System, Structure and Function. New York, NY, USA: Oxford University Press; 262-282.

Cazalets J-R, Borde M, Clarac. 1995. Localization of the central pattern generator for hindlimb locomotion in newborn rat. J Neurosci 15: 4943-4951.

Cazalets J-R. 2001. Development of the neural correlates of locomotion in rats. In: Kalverboer AF, Gramsbergen $A$, eds, Handbook of Brain and Behaviour in Human Development. Dordrecht, The Netherlands: Kluwer; 447-466.

Chatterjee S. 1982. Phylogeny and classification of theco-dontian reptiles. Nature 295: 317-320.

Clancy B, Darlington RB, Finlay BL. 2001. Translating developmental time across mammalian species. Neuroscience 105: 7-17.

Crosby EC. 1969. Comparative aspects of cerebellar morphology. In: Llinás $R$, ed, Neurobiology of Cerebellar Evolution and Development. Chicago, Illinois, USA: AMA; 19-42

Deacon TW. 2 002. The human brain. In: Jones $S$, Martin R, Pilbeam D, eds, The Cambridge Encyclopedia of Human Evolution. Cambridge, UK: Cambridge University Press; 115-121.

Dobbing J. 1981. The later development of the brain and its vulnerability. In: Davies JA, Dobbing J; eds, Scientific Foundations of Paediatrics, $2^{\text {nd }} \mathrm{ed}$. London, UK: William Heinemann; 744-758.

Dover G. Anti Dawkins. 2000. In: Rose H, Rose S, eds, Alas, Poor Darwin, Arguments Against Evolutionary Psychology. London, UK: Jonathan Cape; $47-66$

Ebbeson SOE. 1976. Morphology of the spinal cord. In: Llinás R, Precht W, eds, Frog Neurobiology. Heidelberg, Germany: Springer; 679-706.

Fleagle JG. 2002. Primate locomotion and posture. In: Jones S, Martin R, Pilbeam D, eds, The Cambridge Encyclopedia of Human Evolution. Cambridge, UK: Cambridge University Press; 75-79.

Forssberg H. Ontogeny of human locomotor control. 1985. I. Infant stepping, supported locomotion and transition to independent locomotion. Exp Brain Res 57: 480-493.

Forssberg H, Dietz V. 1997. Neurobiology of normal and impaired locomotor development. In: Connolly KJ, Forssberg H, eds, Neurophysiology and Neuropsychology of Motor Development. London, UK: MacKeith Press; 78-100.

Geisler HC, Westerga J, Gramsbergen A. 1993. Development of posture in the rat. Acta Neurobiol Exp 53: 517-523.

Geisler HC, Westerga J, Gramsbergen A. 1996. The function of the long back muscles during postural development in the rat. Brain Behav Res 80: 211 215.

Geisler HC, Van der Fits IBM, Gramsbergen A. 1997. The effects of early vestibular deprivation on the motor development in the rat. Brain Behav Res 86: 89-96.

Geisler HC, Gramsbergen A. 1998. Motor development after vestibular deprivation in rats. Neurosci Biobehav Rev 22: 565-569.

Geisler HC, Gramsbergen A. 1998. The EMG development of the longissimus and multifidus muscles after plugging the horizontal semicircular canals. J Vestib Res 8: 399-409.

Gould SJ. 2000. More things in heaven and earth. In: In: Rose H, Rose S, eds, Alas, Poor Darwin, Arguments Against Evolutionary Psychology. London, UK: Jonathan Cape; 85-105.

Gramsbergen A. 1998. Posture and locomotion in the rat: independent or interdependent development? Neurosci Biobehav Rev 22: 547-553.

Gramsbergen A, Van Eykern LA, Taekema HC, Geisler HC. 1999. The activation of back muscles during locomotion in the developing rat. Brain Res Dev Brain Res 112: 217-228.

Grillner S. 1981. Control of locomotion in bipeds, tetrapods and fish. In: Brookhart JM, Mountcastle VB, eds, Handbook of Physiology Section I, The Nervous System, Volume II part 2. Motor Control. Bethesda Maryland, USA: American Physiology Society; 1179-123.

Grillner S, Wallén P, Brodin L, Lansner A 1991. Neuronal network generating locomotor behaviour in lamprey: circuitry, transmitters, membrane properties, and simulation. Ann Rev Neurosci 14: 169-199.

Hadders-Algra M. Development of postural control during the first 18 months of life. Neural Plast 20: 27-36. 
Hadders-Algra M, Brogren E, Forssberg H. 1996. Ontogeny of postural adjustments during sitting in infancy: variation, selection and modulation. $J$ Physiol (Lond) 493: 273-288

Henderson S, Morris J, Frith U. 1981. The motor deficit in Down's syndrome children: a problem of timing? J Child Pyschol Psychiatr 22: 233-245.

Holstege G. 1991. Descending motor pathways and the spinal motor system: limbic and non-limbic components. Prog Brain Res 87: 307-421

Jones EG, Schreyer DJ, Wise SP. 1982. Growth and maturation of the rat corticospinal tract. Prog Brain Res 57: 361-379.

Joosten EA, Gribnau AA, Dederen PJ. 1989. Postnatal development of the corticospinal tract in the rat. An ultrastructural anterograde HRP study. Anat Embryol 179: 449-456.

Kjaerulff O, Kiehn O. 1996. Distribution of networks generating and coordinating locomotor activity in the neonatal rat spinal cord in vitro: a lesion study. J Neurosci 16: 5777-5794.

Kuypers HG. 1982. A new look at the organization of the motor system. Prog Brain Res 57: 381-403.

Lakke E. 1997. The projections to the spinal cord of the rat during development: a timetable of descent. Adv Anat Embryol Cell Biol 135: 1-143.

Lawrence DG, Kuypers HG. 1968. The functional organization of the motor system in the monkey. 1. The effects of bilateral pyramidal lesions. Brain 91: 1-14.

Leakey MG, Feibel CS, McDougall I, Walker A. 1995. New four-million-year-old hominid species from Kanapoi and Allia bay, Kenya. Nature 376: 565-571.

Martin R. 2002. Walking on two legs. In: Jones S, Martin R, Pilbeam D, eds, The Cambridge Encyclopedia of Human Evolution. Cambridge, UK: Cambridge University Press; 78.

Orlovsky GN. 1972. The effect of different descending systems on flexor and extensor activity during locomotion. Brain Res 40: 359-371.

Peterson BW, Pitts NG, Fukushima K. 1979. Reticulospinal connections with limb and axial motoneurones. Exp Brain Res 36: 1-20.

Porter R, Lemon R. 1993. Corticospinal function and voluntary movement. Monographs of the Physiological Society, vol 45. Oxford, UK; Clarendon Press; 1-428.

Prechtl HFR. 1984. Continuity and change in early neural development. In: Prechtl HFR, ed, Continuity of
Neural Functions from Prenatal to Postnatal Life. Clinics in Developmental Medicine 94; Oxford, Blackwell Scientific Publishers Ltd; 1-15.

Reisinger E. 1926. Untersuchungen am Nervensystem der Bothrioplana semperi. Z Morphol Ökol Tiere; 5: 119-149.

Romer AS. 1969. Vertebrate history with special reference to factors related to cerebellar evolution. In: Llinás R, ed, Neurobiology of Cerebellar Evolution and Development. Chicago, Illinois, USA: American Medical Associaton; 1-18.

Romijn HJ, Hofman MA, Gramsbergen A. 1991. At what age is the developing cerebral cortex of the rat comparable to that of the full-term newborn human baby? Early Hum Dev 26: 61-67.

Shumway-Cook A, Woollacott M. 1985. Dynamics of postural control in the child with Down syndrome. Physical Ther 65: 1315-1322.

Stringer CB. 2002. Evolution of early humans In: Jones S, Martin R, Pilbeam D, eds, The Cambridge Encyclopedia of Human Evolution. Cambridge, UK: Cambridge University Press; 241-251.

Swinny JD, van der Want JJL, Gramsbergen A. 2005. Cerebellar development and plasticity: perspectives for motor coordination strategies, for motor skills, and for therapy. Neural Plast 20: 81-88.

Ten Donkelaar HJ. 1982. Organization of descending path-ways to the spinal cord in amphibians and reptiles. Organization of descending pathways to the spinal cord in amphibians and reptiles. Prog Brain Res 57: 25-67.

Van der Fits IBM, Otten E, Klip AWJ, Van Eykern LA, Hadders-Algra M. 1999. The development of postural adjustments during reaching in healthy infants aged 6-18 months: evidence for two transitions. Exp Brain Res 126: 517-528.

Vinay L, Bussieres N, Shupliakov O, Dubuc R, Grillner S. 1998. Anatomical study of spinobulbar neurones in lampreys. J Comp Neurol 397: 475-492.

Vinay L, Brocard F, Pflieger JF, Simeoni-Alias J, Clarac F. 2000. Perinatal development of lumbar moto-neurones and their inputs in the rat. Brain Res Bull 53: 635-647.

Visser JE, Bloem BR. Role of the basal ganglia in balance control. Neural Plast 20: 89-101.

Ward CV, Leakey MG, Walker A. 2001. The earliest known australopithecus, $A$. anamensis. J Human Evolut $41: 255-368$.

Westerga J, Gramsbergen A. 1990. The development of locomotion in the rat. Dev Brain Res 57: 163-174. 
Westerga J, Gramsbergen A. 19 93. Changes in the EMG of two major hindlimb muscles during locomotor development in the rat. Exp Brain Res 92: 479-488.

Westerga J, Gramsbergen A. 1994. Development of the EMG of the soleus muscle in the rat. Dev Brain Res 80: 233-243.

Whishaw IQ, O'Connor WT, Dunnett SB. 1986. The contributions of motor cortex, nigrostriatal dopamine and caudate-putamen to skilled forelimb use in the rat. Brain 109:-805-843.

Whishaw IQ, Metz GA. 2002. Assessment of the pyramidal tract contribution to skilled movement in the rat: Absence of impairments or recovery mediated by the uncrossed pyramidal tract in the rat versus enduring deficits prodced by the crossed pyramidal tract. Behav Brain Res 134: 323-336

White TD, Suwa G, Asfaw B. 1994. Austraolopithecus ramidus, a new species of early hominid from Aramis, Ethiopia. Nature 371: 306-312.

Wood BA. 2002. Evolution of australopithecins In: Jones S, Martin R, Pilbeam D, eds, The Cambridge Encyclopedia of Human Evolution. Cambridge, UK: Cambridge University Press; 231-240. 

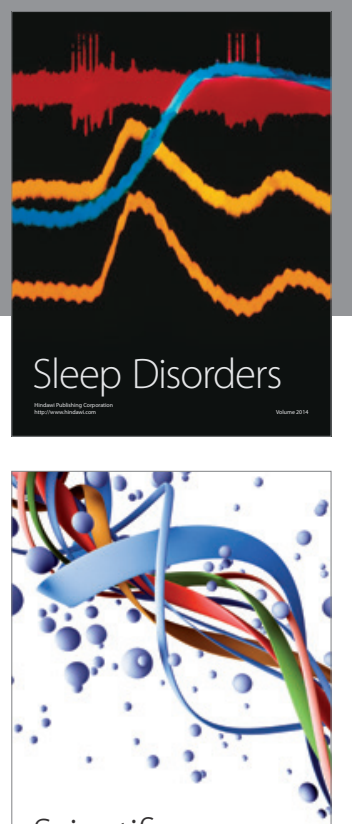

Scientifica
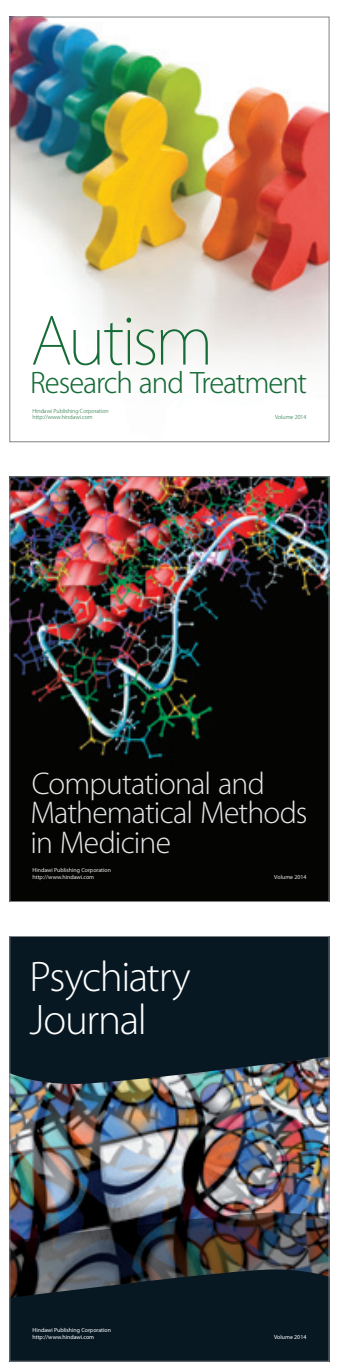
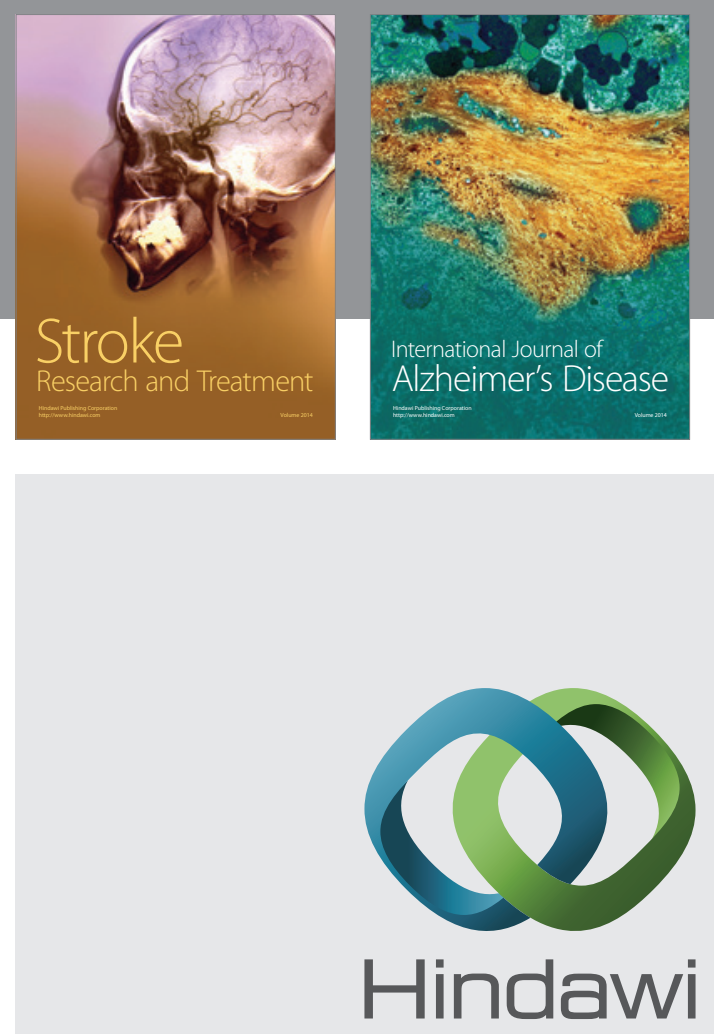

Submit your manuscripts at

http://www.hindawi.com
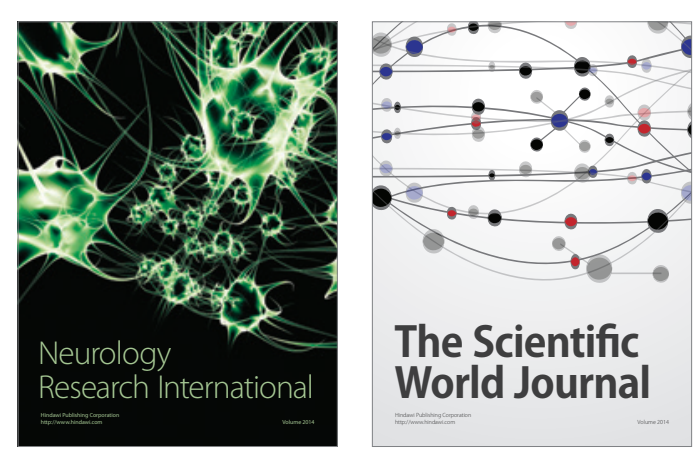

The Scientific World Journal

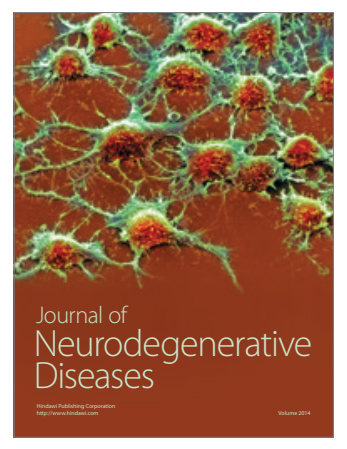

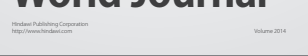

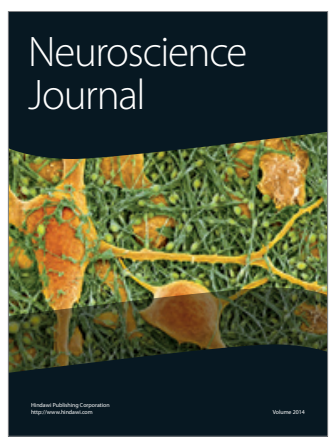

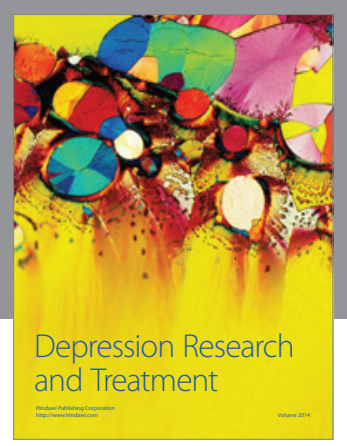
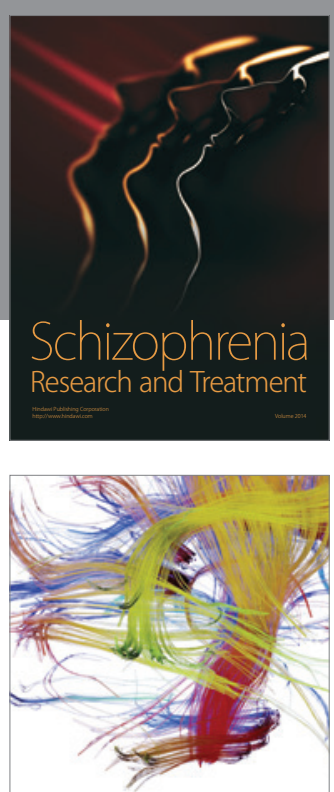

Brain Science

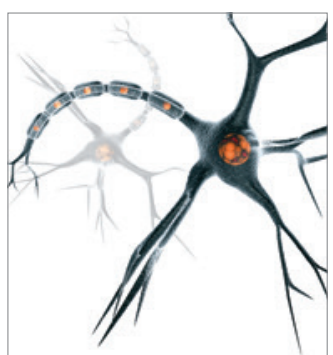

Neural Plasticity
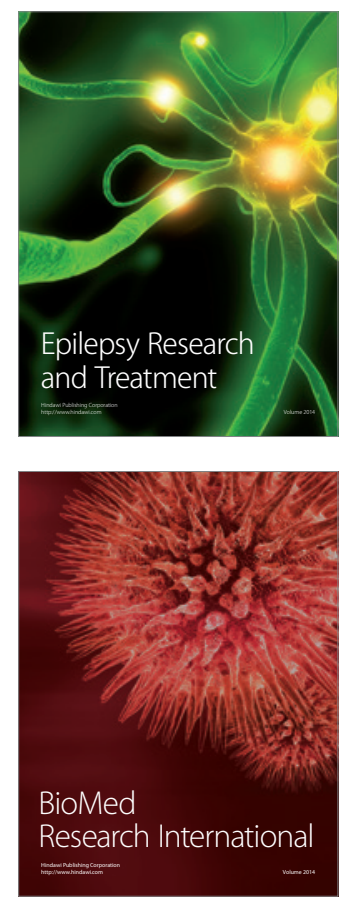

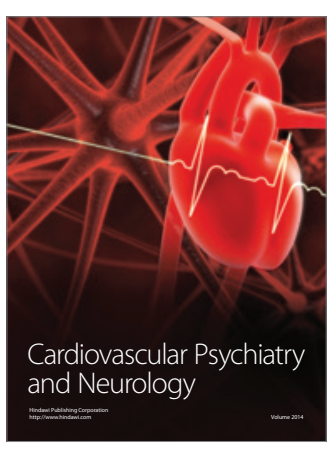

Parkinson's

Disease
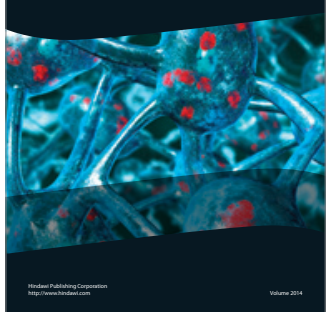